\title{
Verifying exchange between Aeronautics and Oil\&Gas industries through Lateral Thinking
}

\author{
Francisco Tarcísio Guedes Lima Verde Neto ${ }^{a}$, Luis Gonzaga Trabasso ${ }^{b}$ \\ a Divisão de Engenharia Aeronáutica, Instituto Tecnológico de Aeronáutica - ITA, São José dos Campos, São Paulo, Brasil \\ b Divisão de Engenharia Mecânica, Instituto Tecnológico de Aeronáutica - ITA, São José dos Campos, São Paulo, Brasil \\ e-mails: tarcisiolv@gmail.com, luis.gonzaga@sc.senai.br
}

\begin{abstract}
Human Factor is one of the main causes of accidents and operational flaws, especially regarding high reliability organizations. The tendency of human error being fundamental on high-risk activities inspire the need to minimize or prevent its occurrence. The present work figures on this need, seeking to propose design requirements oriented towards human factor. The search for such requirements is through an approach known as lateral thinking. This approach utilizes a series of similarities between two sectors, namely aviation and oil and gas well operations. The search for similarities starts on practices such as the use of Crew Relationship Management (CRM) on well operations, in addition to the validation of Human Factors Analysis and Classification System (HFACS) for accidents on well operations. The analysis uses the theoretical expertise of analogy systematization, in order to find structural alignment between the two industries, under the expressions of analogy studies. Given there exists structural alignment, it is possible to establish exchange opportunities, on which this work concludes suggesting which expertise on the drilling industry can help make Single Pilot operations viable within the aircraft domain. The present work purposes to characterize an analogy between the oil well driller and the airplane pilot workstations through the systemic comprehension of human factors, indicating exchange possibilities between them, using the premises on the Structure-Mapping Engine (SME).
\end{abstract}

Keywords: human factors, lateral thinking, technological exchange.

\section{Introduction}

As the frequency of equipment failures decreases with technological advances, the influence of human factors has been increasingly apparent (Gordon, 1998). The study of human factors has been a key issue in industries that involve critical operations. In the aviation industry, specifically, human factor experts are part of design and organizations (Johnsen, 2014). The oil well drilling industry, also an industry of critical operations and high impact and with a high level of technology, has taken human factors into consideration late, if compared to other industries (Johnsen, 2014). The main effort of IOGP (International Association of Oil and Gas Producers) is implementing CRM (Crew Resource Management) trainings on well operations' teams (International Association of Oil \& Gas Producers, 2014a).

The objective of the Human Factors field is to design human interaction with systems in order to improve performance and user satisfaction and increase safety (Wickens et al., 2014). As Human Factors present itself in a unique way, its measuring needs to take some specificities into account while observing phenomena with physical criteria even though it is a behavioral science derived from
Psychology (Meister, 2003). Human Factors Science is object oriented, not content oriented, so its area of interest is hard to define, as it relates to multiple other disciplines, such as seen on Figure 1 (Wickens et al., 2014).

If the oil and gas industry is analyzed, circa $90 \%$ of the accidents have a Human Factor cause (Johnsen, 2014). In addition, there is an effort by IOGP to implement safeguards related to human factors, especially in the implementation of CRM, studied in its 501 report (Flin, Wilkinson et al. 2014) and indicated for implementation in its 502 report (International Association of Oil \& Gas Producers, 2014b).

CRM is consolidated since 1993, first appearing as Cockpit Resource Management, instead of the most recent Crew Resource Management (Kanki et al. 2019). The usage of CRM in Well Operations indicates the possibility of an analogy. Studies show that analyzing industry similarities can provide innovative solutions (Gassmann \& Zeschky, 2008). Figure 3 shows a systematization for solution search through different industries.

The temporal differences in approach show that the aeronautical sector has great expertise addressing human 


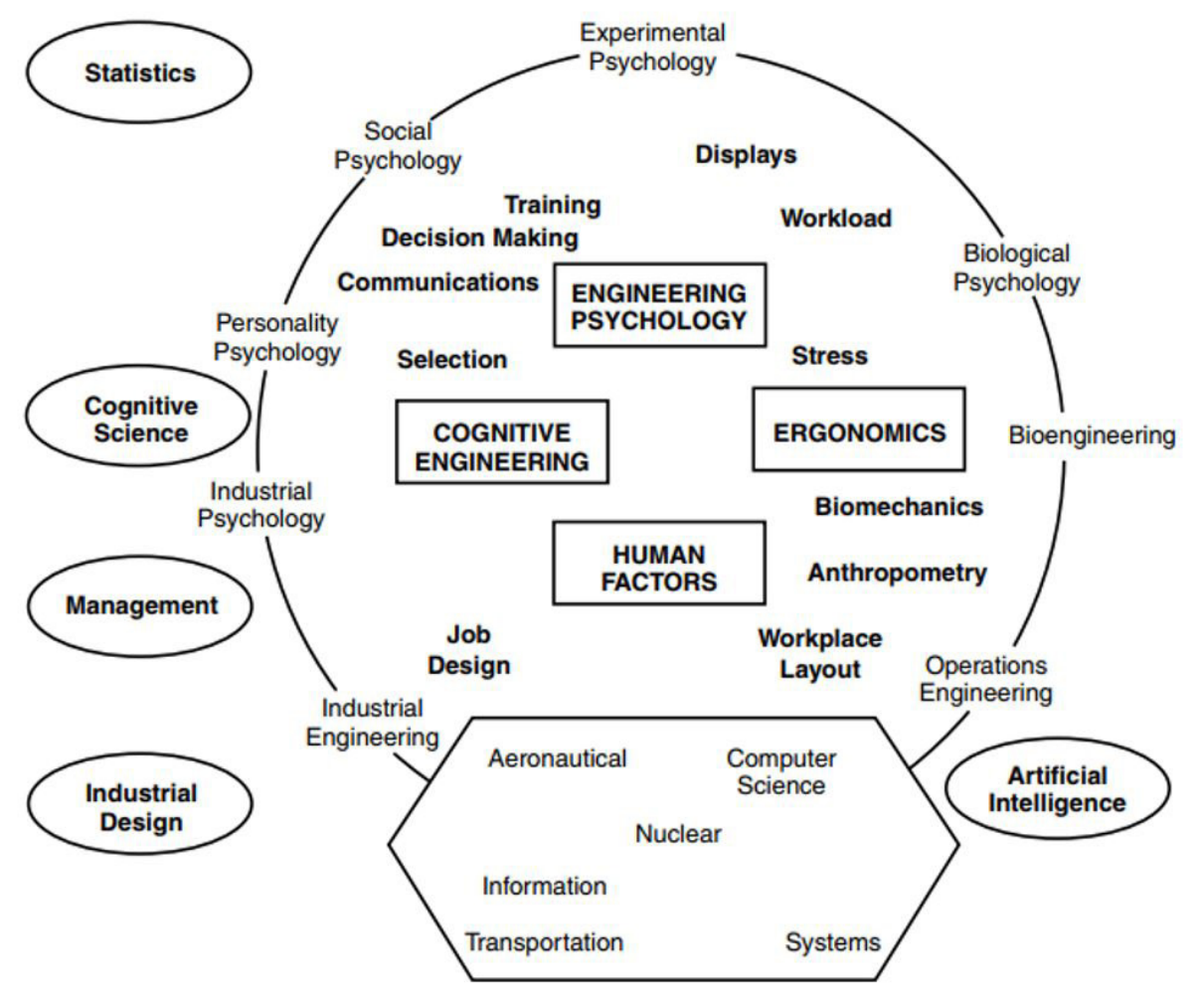

Figure 1. Human Factors and Related Disciplines (Wickens et al., 2014).

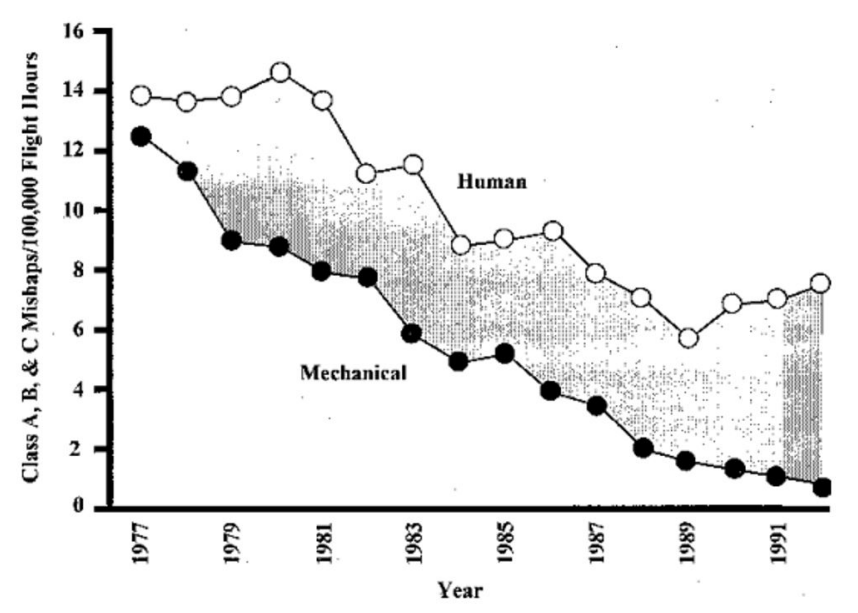

Figure 2. Aviation accidents per primary cause (Wiegmann \& Shappell, 2017).

factors, and that human factors policies in aviation are a path for the oil industry, being a source of learning and growth from in efficiency and operational security. However, this approach would not include, for example, the possible knowledge exchange between industries, according to their experiences and peculiarities.

Figure 2 shows the ratio of causes for aviation accidents, showing that, as technology improves, the human factors play a major role on the cause of such accidents. The majority of aviation accidents ( 70 to $80 \%$ ) can be somehow related to the Human Factor, showing its importance (Wiegmann \& Shappell, 2017).

The present work purposes to characterize an analogy between the oil well driller and the airplane pilot workstations through the systemic comprehension of human factors, indicating exchange possibilities between them. The choice to analyze both workstations is the superficial similarities between them, and this work purposes to state that, given there is a visual similarity and the prevalence of human factors as a cause for accidents, the possibilities of exchange exist not only visually, but eventually on processes and design elements.

\section{Objectives and methodology}

The main objective of the present work is to assess the viability of exchange between the oil and gas industry and the aviation industry. The viability of exchange is verified through Similarity Analysis, using the premises of the Structure-Mapping Engine (SME). To assess such viability, the first step is to identify the similarities between both industries, in direct correspondence. The second step is to verify the processes and practices that indicate the possibility of the analogy, demonstrating relations between the elements of similarity.

On the first step, the elements that indicate the possibility of an analogy are selected. Given that some practices already stated, such as Crew Resource Management (CRM), indicate 


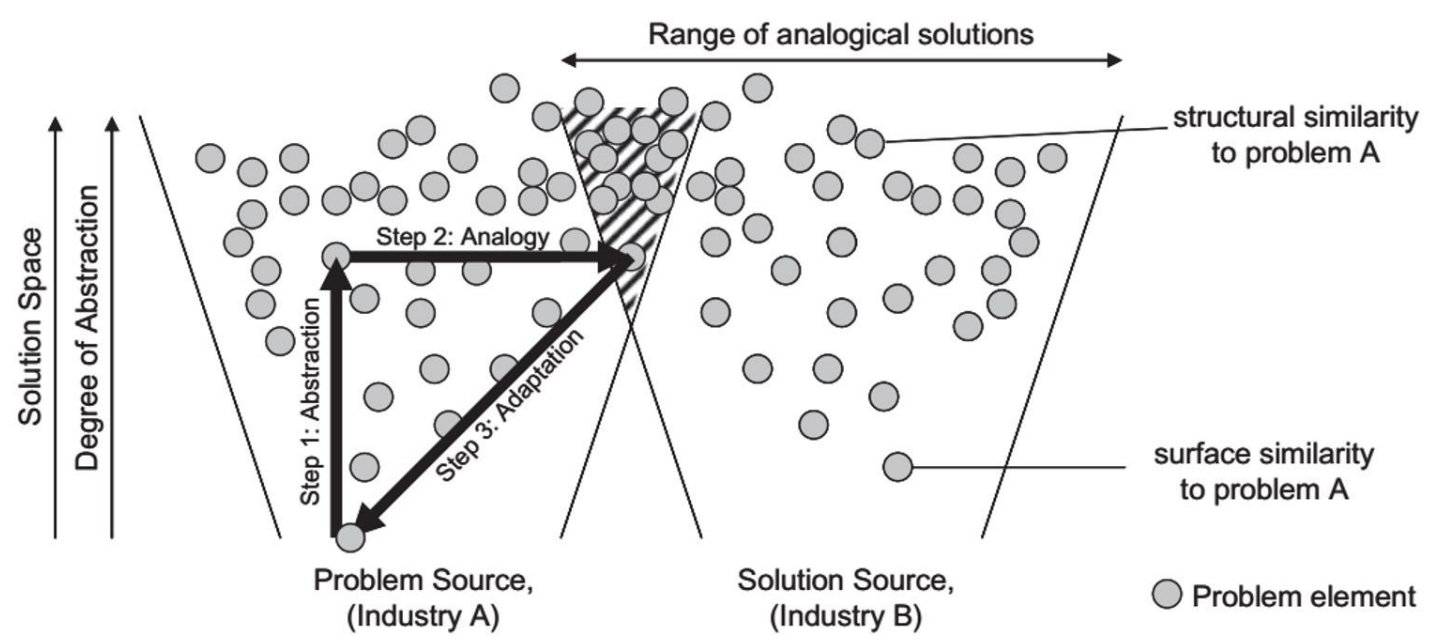

Figure 3. Broadening the Solution Space through abstraction (Gassmann \& Zeschky, 2008).

a relational correspondence, the second step is to identify new relational structures. This identification is done through the analysis, with a team of experienced well engineers, of the IADC Safety Alerts database using the Human Factors Analysis and Classification System (HFACS). Finally, to verify the exchange possibility, the viability of design concepts from the oil and gas industry on an aviation recurring problem must be analyzed. This analysis observes challenges for the implementation of Single Pilot Operations, and the possible solutions originated on the oil and gas industry. A questionnaire is performed on a group of professional with a drilling expertise to state that drilling and intervening on a well with a single operator are possible and already tested, serving as an inspiration for aviation systems solutions.

\section{Lateral thinking and analogies}

Lateral thinking is a methodological approach based on a deficiency that traditional methods of developing solutions have, called vertical thinking (De Bono, 2015).

Vertical thinking is a methodological approach that works within established patterns, developing them and looking for solutions within an established knowledge structure (De Bono, 2015). On the other hand, Lateral thinking is not about discarding established patterns, but changing them, or looking in another way. When working through vertical thinking, each step of development is theorized until a coherent conclusion, but this conclusion is not necessarily the best possible solution. Figure 4 shows two different rationales that illustrate the limitations of vertical thinking. On the left side, the rectangle rationale is used, but at the final step of the assembly it cannot provide a solution. In the right side, a different rationale makes the assembly possible.
Figure 4 shows that different paradigms can be definitive for the solution of a problem. Also, the will to surpass such paradigms is mandatory to find innovative solutions. (Gassmann \& Zeschky, 2008).

Lateral thinking uses different approaches for generating ideas. One of them is analogy, which takes new ideas from observable relations. Such relations can refer to objects or processes (De Bono, 2015). Figure 5 puts side by side a well operations control cabin and an airplane cockpit. At first sight there are visual similarities on the command systems, however, to validate such analogy, a more detailed study must be done.

\section{Systematic approach on analogy for innovation}

The analogy approach is frequently used on innovation as it is able to stimulate it. For example, a bicycle analogy helped the Wright Brothers design a controllable airplane (Hope et al., 2017).

The premise for analogy problem solving is to turn the problem into an analogy, and from the analogy, solve the problem (De Bono, 2015). The analogy skill can be defined as the ability to recognize common relational structures in different contexts, and analogy can be defined as a kind of similarity that preserves relational structures in different sets of elements (Gentner \& Maravilla, 2017). To map an analogy, it is necessary to search for structural alignment between two systems, according to its common relational structures. (Gentner \& Maravilla, 2017).

There are implicit constraints that indicate the validity of an analogy, such as direct correspondence and parallel connectivity, as one can see on Figure 6 (Gentner \& Maravilla, 2017). Direct correspondence is when a system presents the same objects or elements, as parallel connectivity presents the same relational structure between such elements. (Gentner \& Maravilla, 2017). 

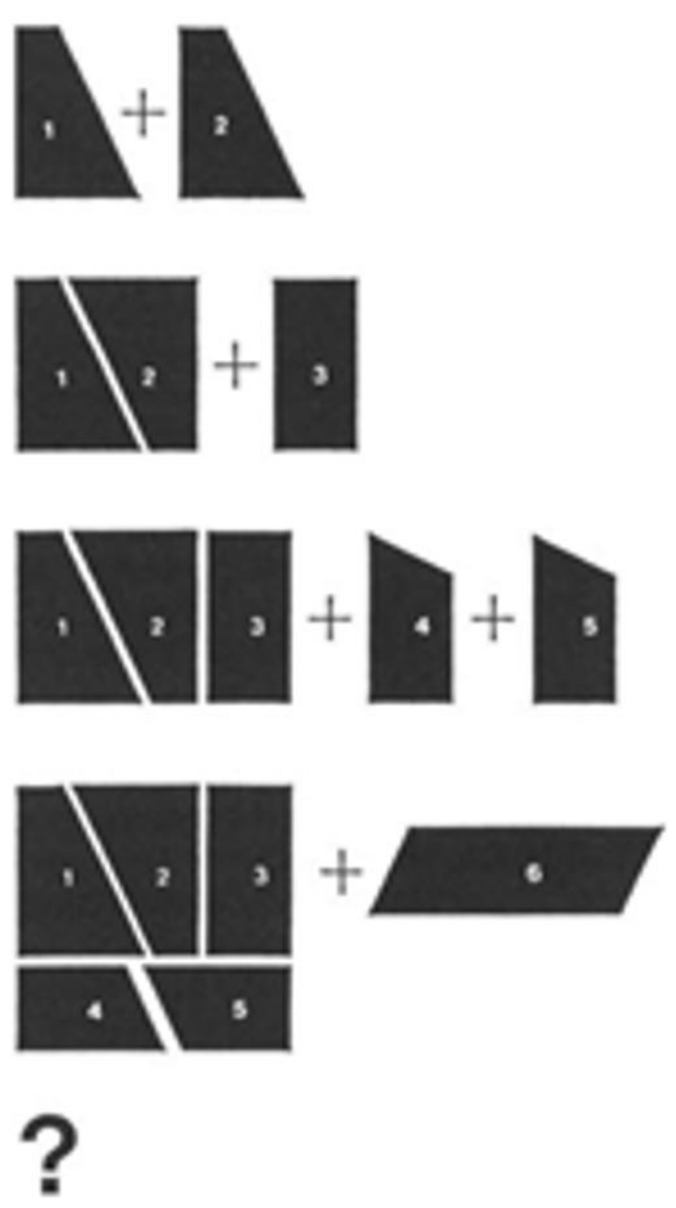

Figure 4. Vertical Thinking Limitations (De Bono, 2015).

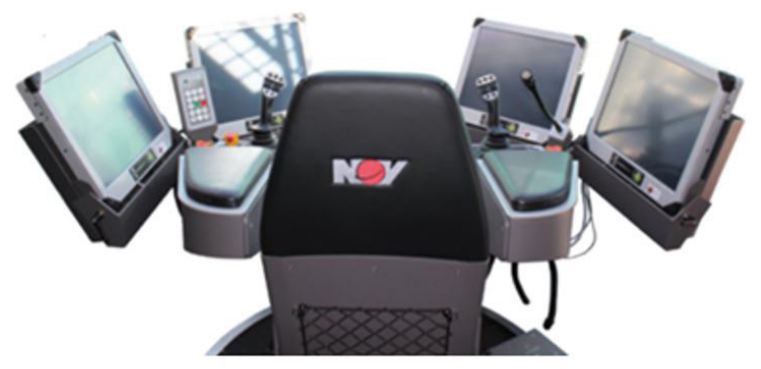

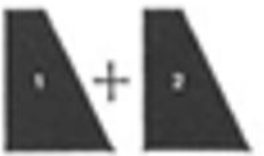
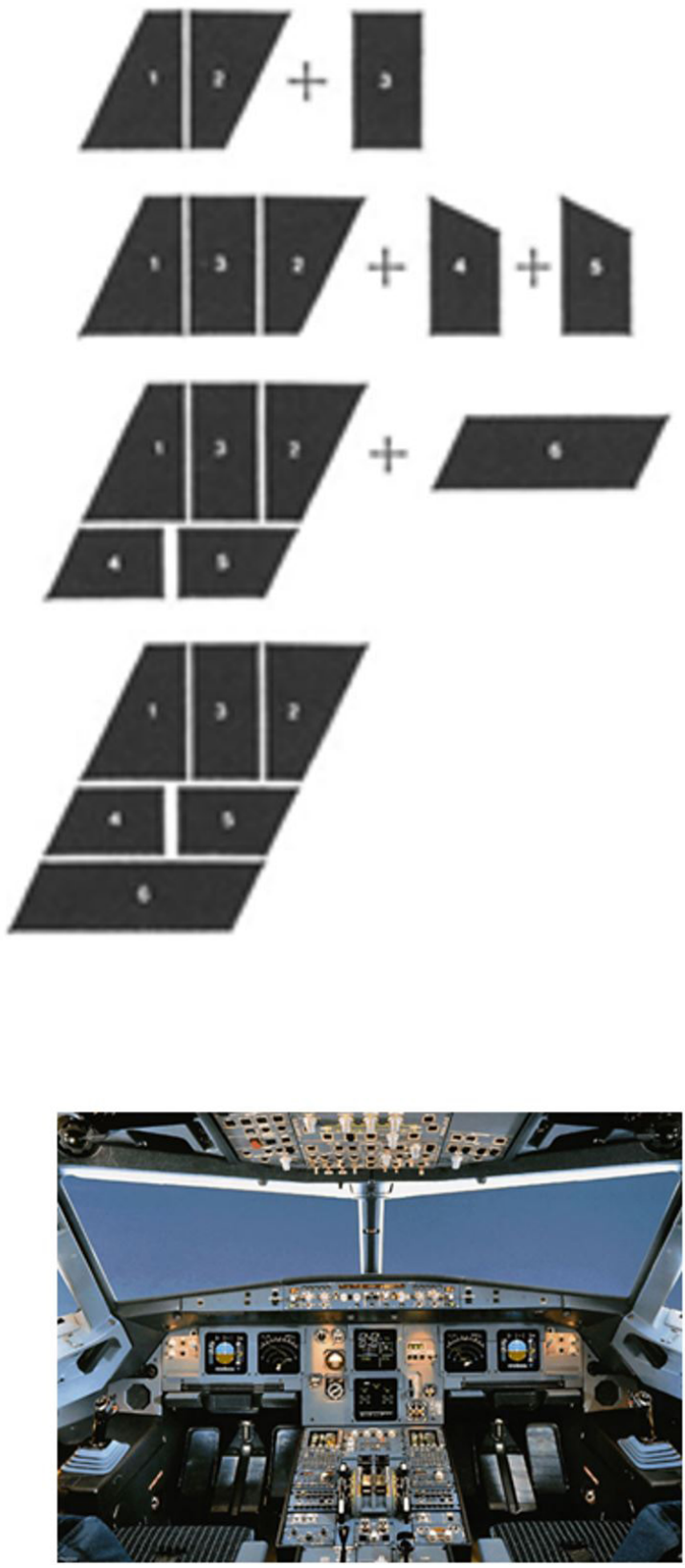

Figure 5. Driller Chair (NOV, 2018) and airplane cockpit (International Civil Aviation Organization, 2017).

Some conclusions are possible through structural alignment, as it indicates the possibility of an inference through analogy, as seen on Figure 7. Searching for inference through analogy can be synthesized on a tool called SME (Structure-Mapping Engine), a computational tool designed to analyze the structural coherence of the analogy, searching for possible candidates for analogies, by comparing objects on different systems. Then it focus on structural consistency in order to highlight the relations systems which are more coherent (Gentner \& Maravilla, 2017).

Terminology matters for the study of analogies as similarities are different from analogies. Similarities are not only relational but also about the properties of elements, 


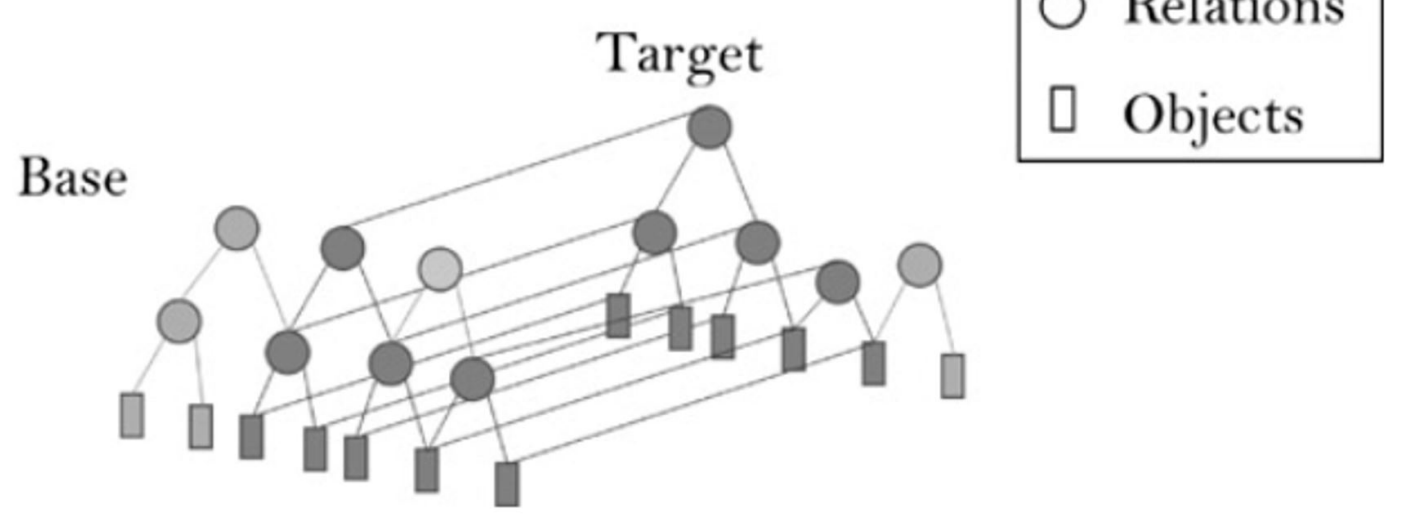

Figure 6. Structure Mapping Scheme (Gentner \& Maravilla, 2017).

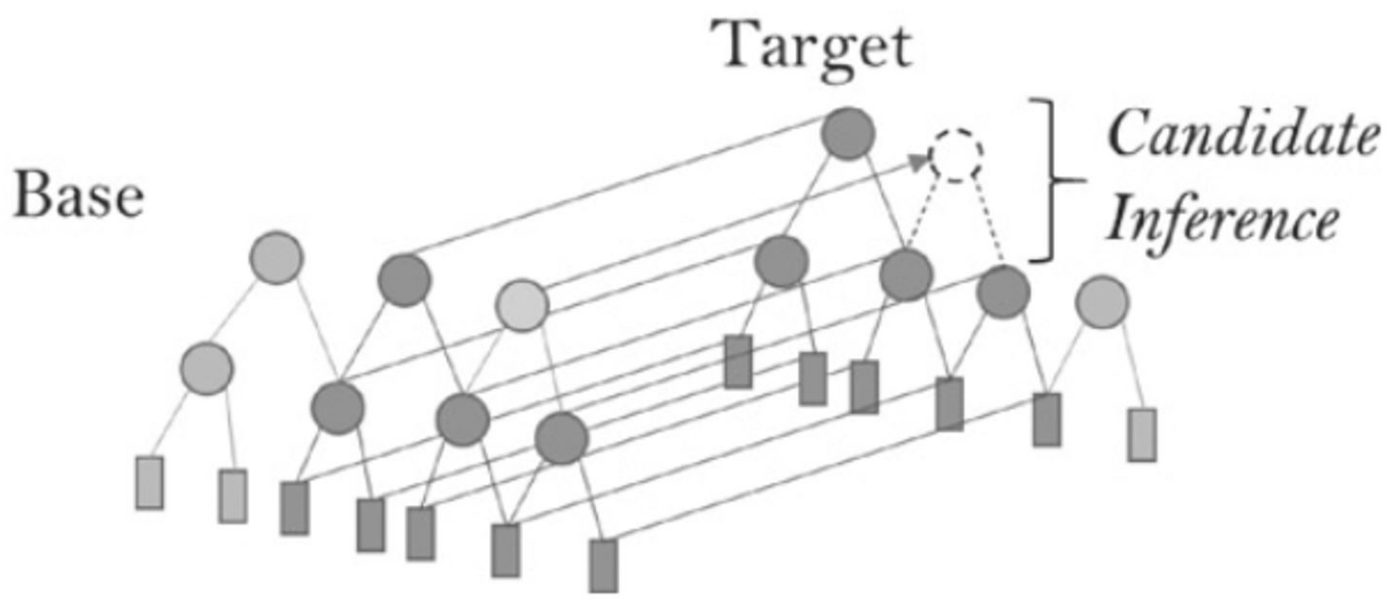

Figure 7. Inference model based on structural alignment (Gentner \& Maravilla, 2017).

and analogies focus on the relational structures (Gentner \& Maravilla, 2017).

Similarities can be superficial or structural, the former being more utilized for characterizing an analogy (Blanchette \& Dunbar, 2000).

This work purposes to characterize, through human factors, a structural alignment between the oil and gas industry and the aviation industry. The presumption is that, as there is a superficial similarity as per Figure 5, one can abstract into a structural similarity in order to assure the possibility of exchange.

Mapping to describe analogies is important as it can highlight analogies such as:

- A steam engine uses fuel to generate energy.

- A mythocondria uses fuel (glucose) to generate energy in the form of ATP. (Gentner \& Maravilla, 2017).
Although there are no superficial similarities, the presence of the elements "energy" and fuel (glucose) and the relation between them makes the analogy feasible. The same must be done when analyzing work stations. Creating an element system is necessary to verify possible relations. As this work deals with human factors, it is hard to work with the premises on SME, as being a computational tool, it needs more formal structures and measures. However, it is possible to establish the same methodology, from objects to relations, or from specific to general elements. To do so, it is necessary to present the common elements in the two systems:

- Human operator starring the tasks. (H)

- Auxiliary crew fundamental to the completion of tasks. (C)

- High level of human related accidents. (A) 
- Sophisticated Machines, with the presence of digital panels and sidesticks. (M)

- Organizations with a great level of standardization and detailed procedures. $(\mathrm{O})$

The presence of such elements indicate superficial similarities as seen on Figure 8:

Through the similarities indicated on Figure 8, it is necessary to abstract into the level of relations. For example, the use of CRM and WO-CRM (Well Operations Crew Resource Management) in both industries, already verified by experience, allows us to state that the human operator relates to its crew by the CRM or WO-CRM policies. The mutual applicability of CRM is useful to indicate there is a structural consistency on this subset of relations, as CRM is a whole universe of policies.

It must be emphasized that CRM involves not only the relations between an operator and his/her crew, but, when observing the themes related to WO-CRM, it relates to teamwork, leadership, communication, decision making, situational awareness and other factors that alter human behavior (International Association of Oil \& Gas Producers, 2014b). That said, the consistency of the structural relation between man and crew is asserted.

The comprehension of other relational structures such as " $\mathrm{H}$ " and "A" can be done through several tools. This work uses the HFACS as a system to analyze the relations between the human operator element and the accidents occurring on the related industry. The verification of such relational alignment can provide a path for the investigation of possible exchanges between industries, as shown on Figure 9.

\section{Human Factors Analysis and Classification System (HFACS): a tool for classifying accidents}

HFACS is a tool for classifying accidents that divides the accidents on 4 major categories, as seen on Figure 10. It has the potential not only to be used on aviation or Oil and Gas, but in other high complexity industries, on which flaws can cause catastrophic losses (Hollaway \& Johnson, 2014). There are alternative approaches to HFACS, as a specific column for regulatory or statutory influences, that can be observed not only on organizational aspects but also from the point of view of a regulation deficiency or a procedural absence (Theophilus et al., 2017).

The Hollaway and Johnson framework, however, allows us to put HFACS classifications in the drilling industry together with the aviation classifications, using the Safety Alerts on the IADC (International Association of Drilling Contractors) website to verify the alignment stated on Figure 9 (International Association of Drilling Contractors, 2019).

At first, a group of professionals from the well operations field analyzed the relevance of human factor on all IADC
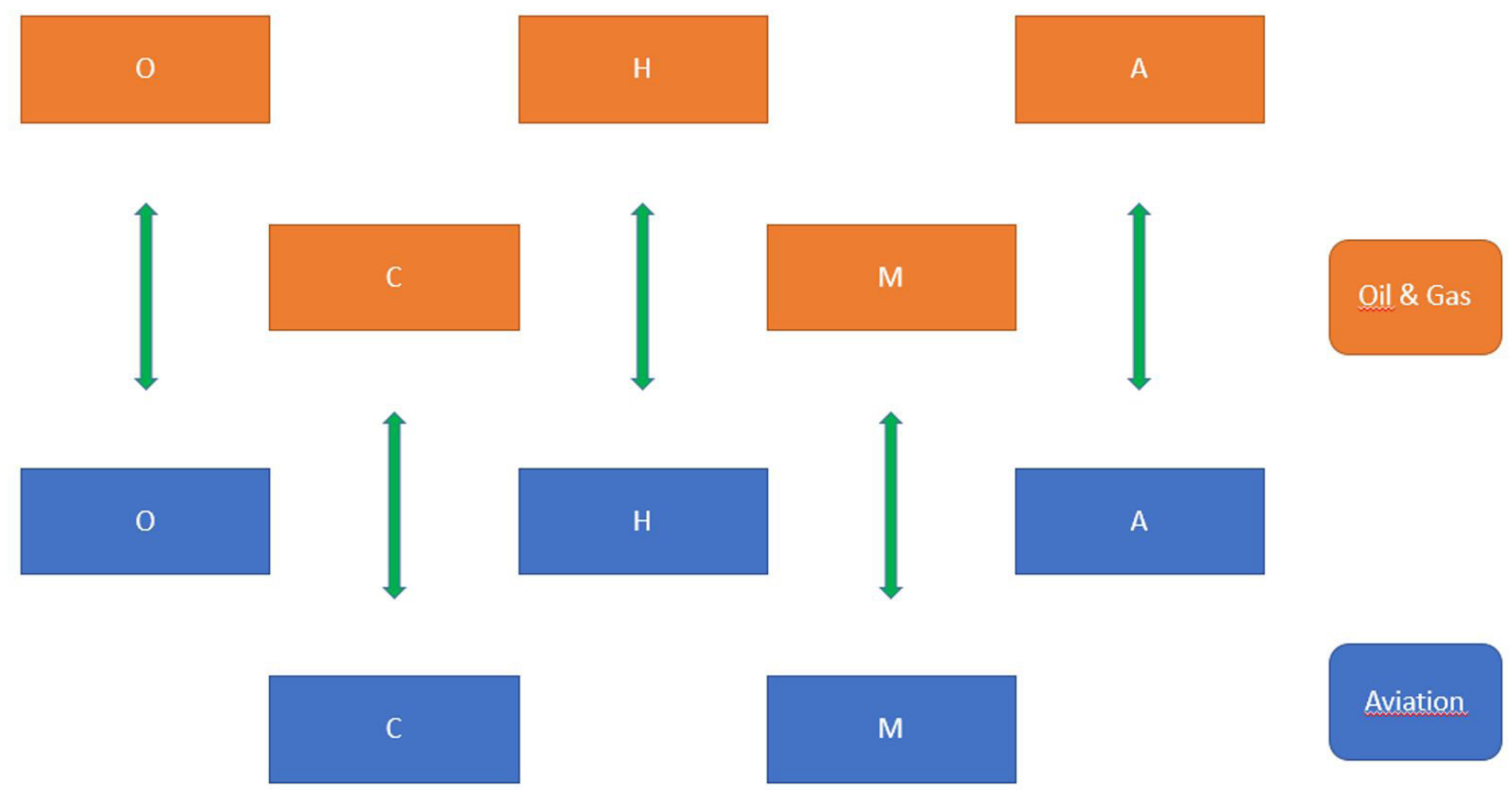

Figure 8. Superficial similarity indication between industries. 
accidents from 2014 to 2019, and which of those accidents were related to the driller or the drillfloor, and, from such accidents, those related to human factors. The first screening of accidents is presented on Table 1. The HFACS classification is presented on Table 2.

Human factor is a relevant theme on IADC Safety Alerts, with $74 \%$ of total accidents analyzed, the driller is involved in $44 \%$ of the activities, and, in $79 \%$ of those, human factor was directly related. On Table 2, the most relevant Human Factor indicated is "Communication, Coordination and Planning", on 11 from 19 alerts analyzed. "Mental States" and "Planned Inapropriate Operations", are also relevant. The latter refers to operations that should be properly analyzed by the driller specifically.

HFACS is a tool of accident investigation, so there is a bias on such analysis, as the alert is already disclosed, that is, after the investigation. Not all the necessary factors for an accurate classification are present, however for the purpose of this work - the observation of HFACS' effectiveness and the comparison of flaws found on Well Operations with those found on Aviation - it suffices.

In possession of gathered data, a comparison is made with the data for the Naval Aviation, on Figure 11, which shows the rate of Class A accidents related to any HFACS category.

HFACS is a tool that can diagnose systemic issues at given industry. In this analysis, it is possible to infer that HFACS can portray an accurate diagnosis on the Drilling Industry in comparison to the aviation. For the record, "Communication, Coordination and Planning" and "Planned Inappropriate Operations" stand out precisely by the specificities of the driller's work in comparison to the pilot.

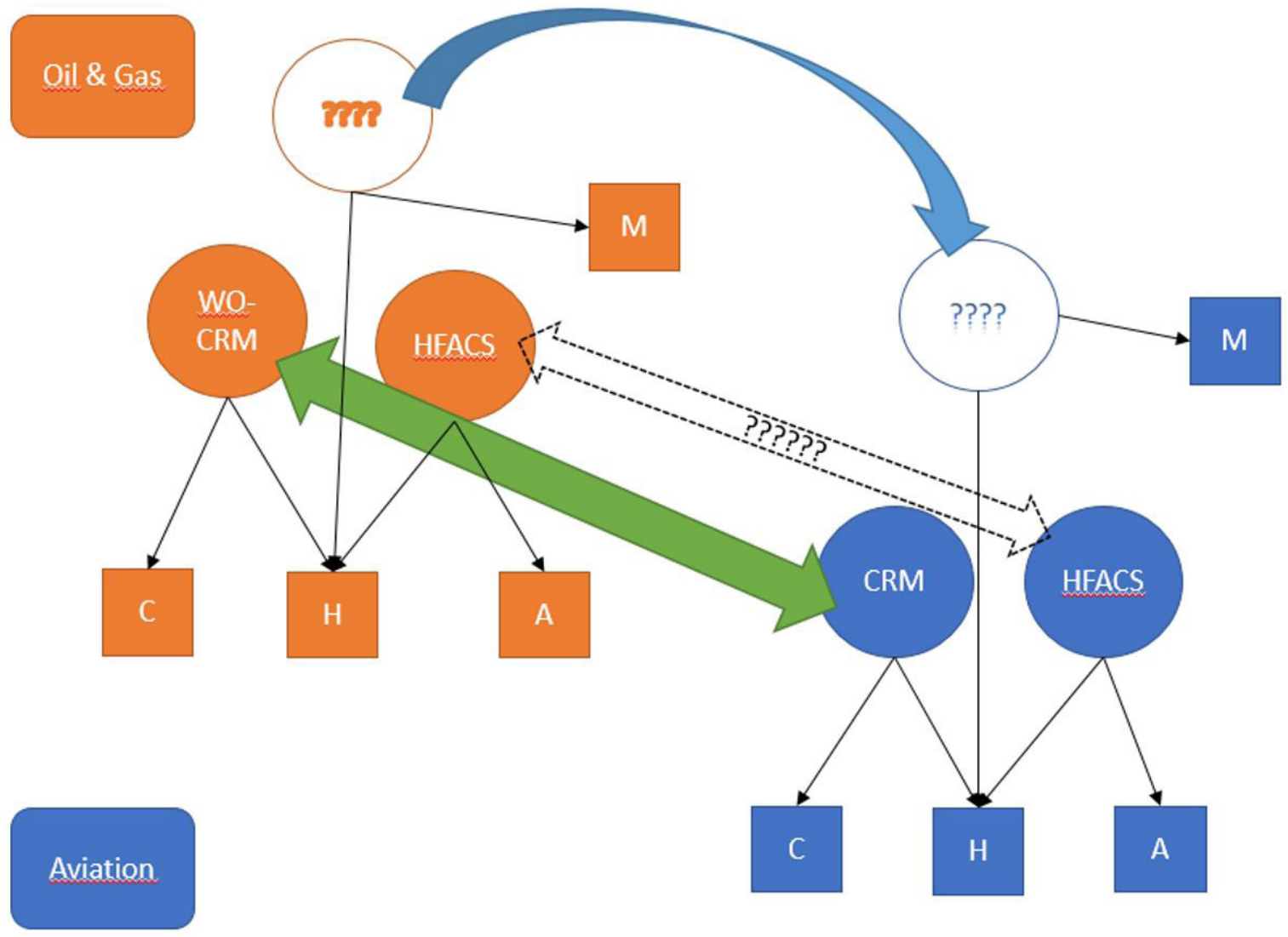

Figure 9. Purposed Structural Alignment

Table 1. Relevance of Human Factors and Driller involvement on IADC Safety Alerts.

\begin{tabular}{|c|c|c|c|}
\hline YEAR & Total ACCIDENTS & HUMAN FACTOR PREVALENCE & $\begin{array}{c}\text { DRILLER RELATED OCURRENCE } \\
\text { (HUMAN FACTORS) }\end{array}$ \\
\hline 2014 & 30 & 21 & $13(9)$ \\
\hline 2015 & 10 & 10 & $5(5)$ \\
\hline 2016 & 0 & 0 & $3(0)$ \\
\hline 2017 & 6 & 3 & $2(2)$ \\
\hline 2018 & 3 & 2 & $1(1)$ \\
\hline 2019 & 5 & 4 & \\
\hline
\end{tabular}



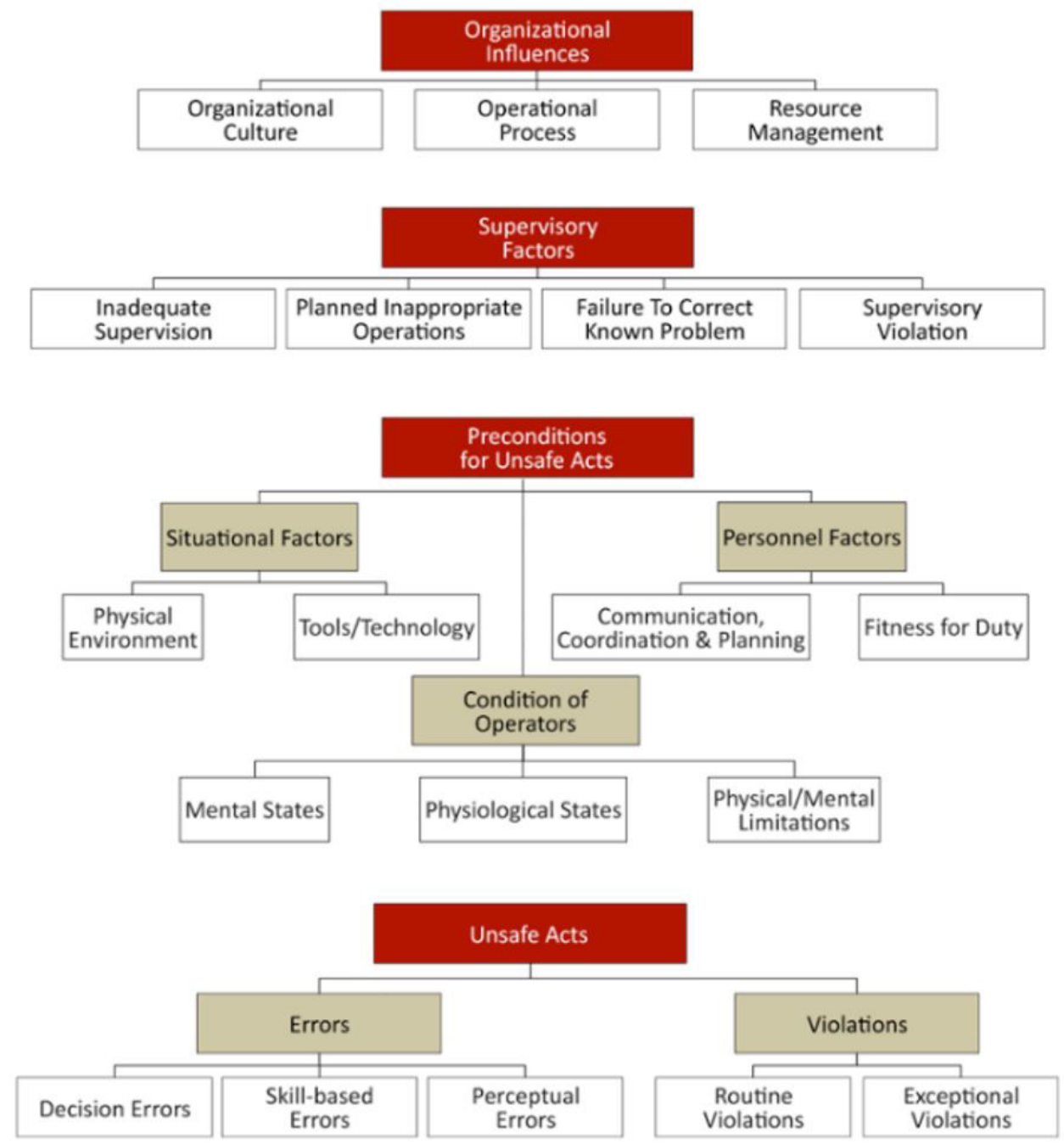

Figure 10. HFACS categories (Human Factors Analysis and Classification System, 2014).

Table 2. HFACS Classification on IADC Alerts.

\begin{tabular}{|l|l|c|}
\hline \multicolumn{1}{|c|}{ Classification } & \multicolumn{1}{|c|}{ Causal Categories } & Total \\
\hline \multirow{4}{*}{ Supervisory Factors } & Inadequate Supervision & 5 \\
\cline { 2 - 3 } & Planned Inappropriate Operations & 2 \\
\cline { 2 - 3 } & Failure to Correct Known Problems & 3 \\
\cline { 2 - 3 } & Supervisory Violation & 6 \\
\hline \multirow{2}{*}{ Preconditions for Unsafe Acts - Situational Factors } & Tools / Technology & 3 \\
\cline { 2 - 3 } & Physical Environment & 11 \\
\hline \multirow{2}{*}{ Preconditions for Unsafe Acts - Personnel Factors } & Communication, Coordination \& Planning & 2 \\
\cline { 2 - 3 } & Fitness for Duty & 8 \\
\hline \multirow{3}{*}{ Preconditions for Unsafe Acts - Conditions of Operators } & Mental States & 0 \\
\cline { 2 - 3 } & Physiological States & 3 \\
\cline { 2 - 3 } & Physical / Mental Limitations & 5 \\
\hline \multirow{3}{*}{ Unsafe Acts - Errors } & Decision Errors & 6 \\
\cline { 2 - 3 } & Skill-Based Errors & 4 \\
\cline { 2 - 3 } & Perceptual Errors & 1 \\
\hline \multirow{2}{*}{ Unsafe Acts - Violations } & Routine Violations & 0 \\
\cline { 2 - 3 } & Exceptional Violations & 2 \\
\hline \multirow{3}{*}{ Organizational Influences } & Organizational Culture & 1 \\
\cline { 2 - 3 } & Operational Process & \\
\cline { 2 - 3 } & Resource Management & \\
\hline
\end{tabular}


Therefore, HFACS not only points out the resemblances and structural alignment of both industries, but also highlights what is effectively exchangeable.

The Structural Alignment Purposed in Figure 9 is stablished, being HFACS capable of represent a system of relations between elements " $\mathrm{H}$ " and " $\mathrm{A}$ " of the framework. The next step is to take a closer look on paradigms from the aviation industry, to, through the analogy stated and a lateral thinking approach, lay efforts to find opportunities of exchange. Based on the similarities between the two workstations, this work takes a closer look on Oil\&Gas Drilling industry to find out solutions for the Single Pilot paradigm on the Aviation.

\section{The Single Pilot paradigm and a search for solutions in the Oil\&Gas industry}

The demand for Single Pilot operations rise as the air traffic demand grows, resulting in a growth on pilot demand, in an outlook of scarcity of such professionals (Gearhart, 2018). Single Pilot operations can reduce the demand of pilots by half, reducing company spending with this human resource (Gearhart, 2018). Still, evolution in avionics and automation technologies allow the systems to conduct most stages of the flight, reducing pilot demand (Gearhart, 2018).

Legal requirements, on 14 C.F.R 25.125 \$121.385, define the minimal pilot crew as two pilots, and the certificate owner must designate one pilot as the commander and the other as second in command (USA, 2012).

Searching for technical solutions to enable single pilot operations respecting human factors restraints and operational safety is fundamental to attend this industry demand.

Single Pilot Operations (SPO) seems to be the next step on airlines, given that the piloting crew was reduced from 5

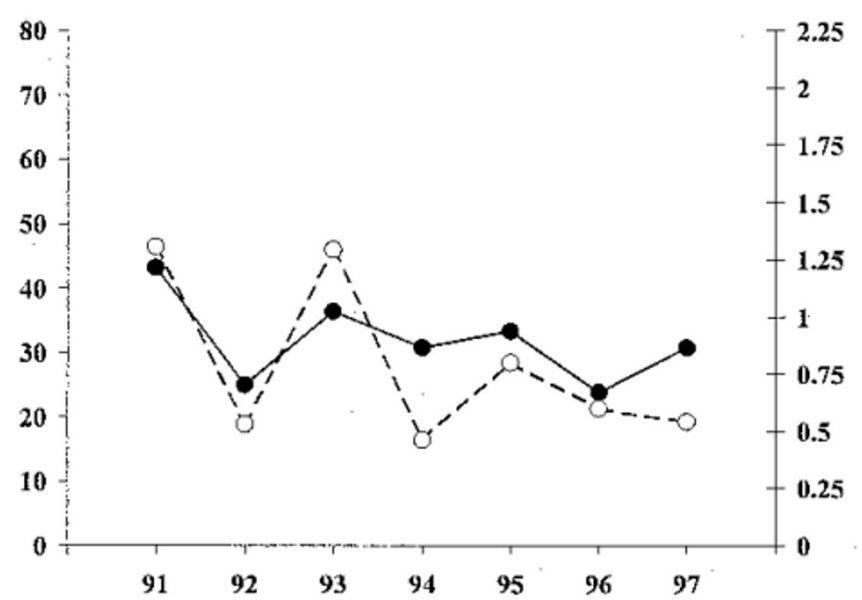

Figure 11. Percentage (closed circle) of Class A accidents related to any HFACS category through the years and its occurrence (open circle) (Wiegmann \& Shappell, 2017). to 2 people, being composed by PF (Pilot Flying) and PM (Pilot Monitoring) or PNF (Pilot Not Flying) (Faulhaber, 2019). SPO relies heavily on CRM as it guaranteed extremely safe operations on aviation (Gearhart, 2018).

A series of procedures in aviation are performed in doubles, being PF responsible for aircraft controls and PNF making contact with Air Traffic Control and filling up checklists. Their communication becomes a cognitive system, keeping all information necessary for aircraft operation on a high level of redundancy (Hutchins, 1995). One of the challenges of SPO is to preserve communication processes and cognition with only one pilot. A Virtual Pilot Assistant (VPA) is an approach to fill this need, being the VPA capable of cooperate with ground team and reducing pilot workload (Lim et al., 2017).

SPO have a concept of a ground team dedicated to support operations, as on Figure 12, with Two Crew Operations (TCO), SPO and Remotely Piloted Aircraft System (RPAS) teams and interactions portrayed.

Cockpits for SPO already exist in military aircrafts and general aviation. Regulations often demand pilots to be able to perform landing through any of the seats, indicating existing SPO concepts on TCO projects (Lim et al., 2017).

The foremost challenges on implementing SPO are:

- Operational: Distribution of Workload between ground team and flight crew, single-pilot resource management (SRM), communication procedures and training necessary for all the crew;

- Technical: Communication Frequency, low latency communication, autonomous navigation and vigilance, adapted automation and interfaces between pilot and ground crew;
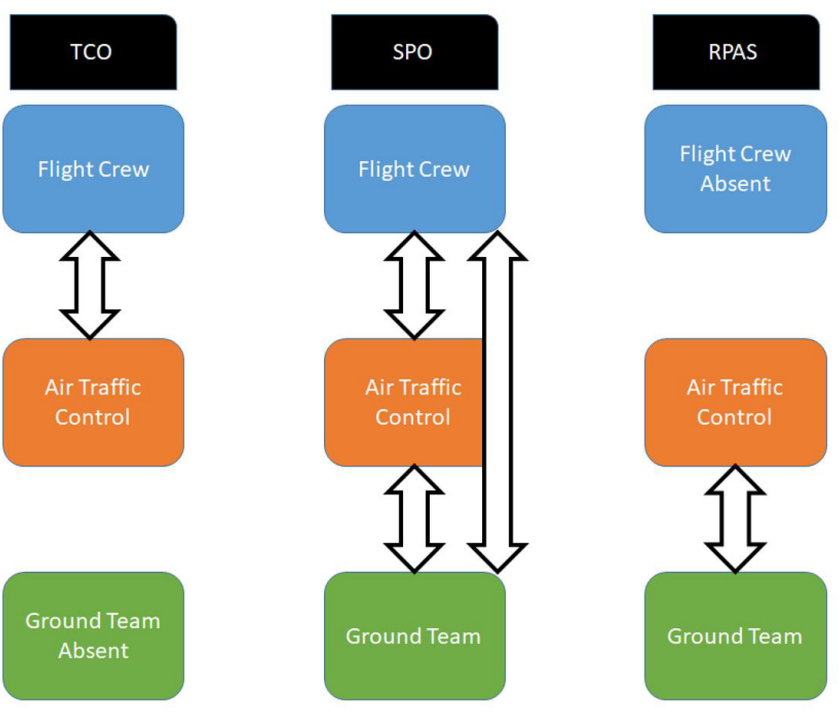

Figure 12. Teams and Interactions Layout for different operations (Lim et al., 2017). 
- Safety: Increase of integrity and performance for the systems, evaluate the impact of high level automation on flight safety, protocol definition for incapacitation;

- Human Factors: Workload assessment, pilot incapacitation, situation awareness assurance between pilot and ground crew, new CRM paradigm with pilot and ground crew interactions, and increase on automation reliance through human machine interface and also interaction (Lim et al., 2017).

Figure 12 and the challenges presented recall the recent projects and operations of drillships and rigs, particularly the efforts on automation and real time monitoring of operations. This indicates that the two industries, through different strategies, head to a common goal of remote operations. That said, it is possible to evaluate the possibility of exchange from the drilling industry to aviation, seeking inspirations to implement SPO.

\section{Real Time monitoring of Operations}

SPO dilemmas, refer to a need for a ground crew working together with the pilot and monitoring the flight on real time. Offshore Well Operations use a robust scheme of real time monitoring of a big amount of data, as seen on Figure 13.

Real time monitoring centers work with specialists and experienced teams, capable of identifying risks and flaws and alert offshore operators of any problem not identified.
In many cases, the proactive action of such center is capable of reduce or mitigate completely damages and unexpected incidents (Iskandar et al., 2018).

Well Operations have a vast experience on real time monitoring, thus, an opportunity for exchange reveals itself. All the expertise of treating a big amount of data with predictive models, and the chain of command designed to operate with such centers can be used to implement a new CRM paradigm in terms of hierarchy and prediction decision.

\section{Single Driller Operations}

Single Driller Operations were the pattern on rig operations, but from 1968 forward, with the implementation of mechanical handling tools, two critical activities started to occur on the drill floor, influencing nowadays drilling systems architecture (Reid, 1998). In 1996, as a way of demonstrating the level of automation on a rig, a kid performed a drillpipe connection using a joystick (Reid, 1998). Figure 14 presents an automated rig in contrast with a non-automated rig. However, even though the first is much more comfortable, drillers report automated operations to impact situational awareness (McLeod, 2015).

Innovations with the purpose to reduce driller workload allow the drillfloor to operate on "autopilot" so the driller can operate less equipment, while some others being operated automatically, with all the necessary automation handshakes necessary to ensure safe operations (Botnan,

\section{/ Real-Time Operation Network Architecture}

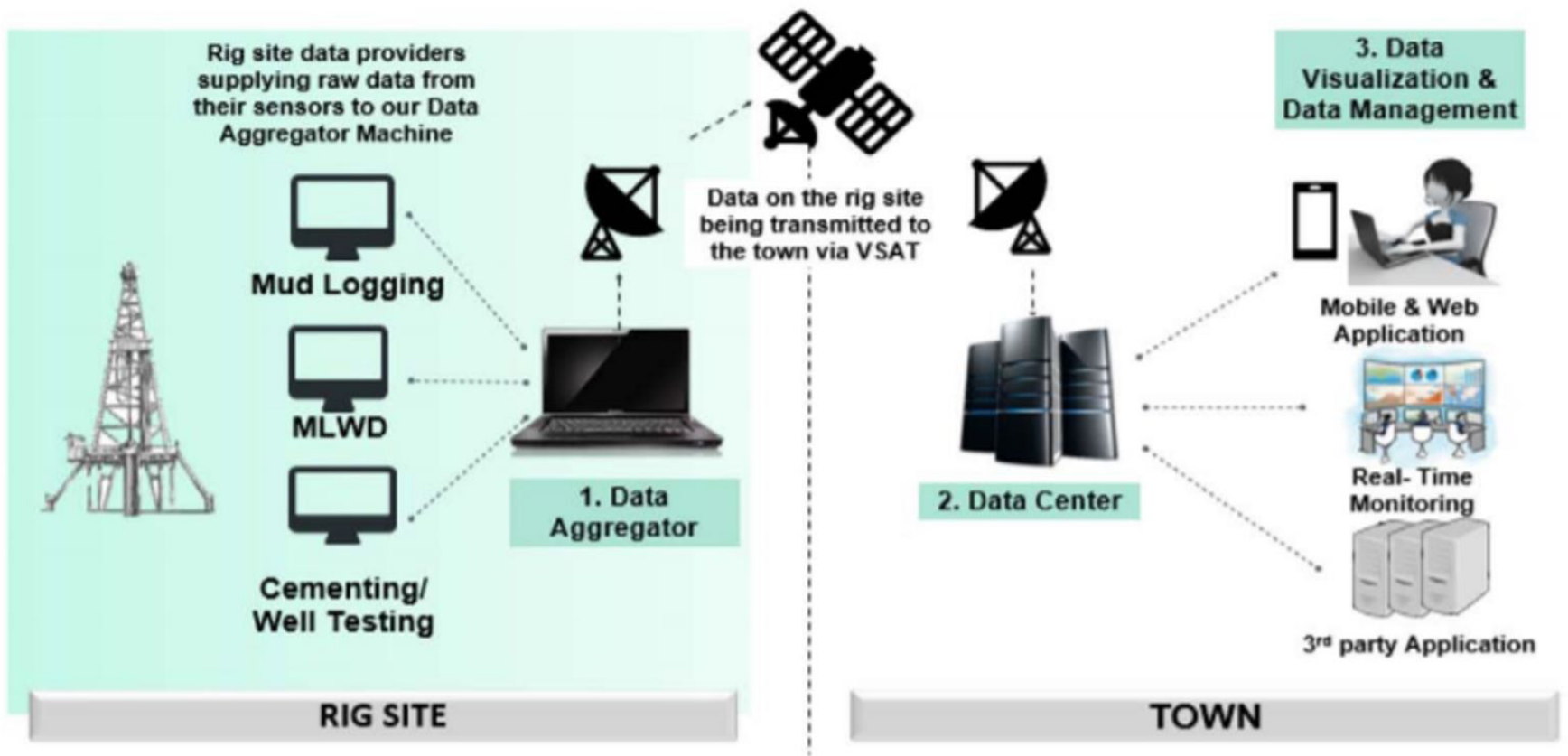

Figure 13. Schematic of real time monitoring on well operations (Iskandar et al., 2018). 


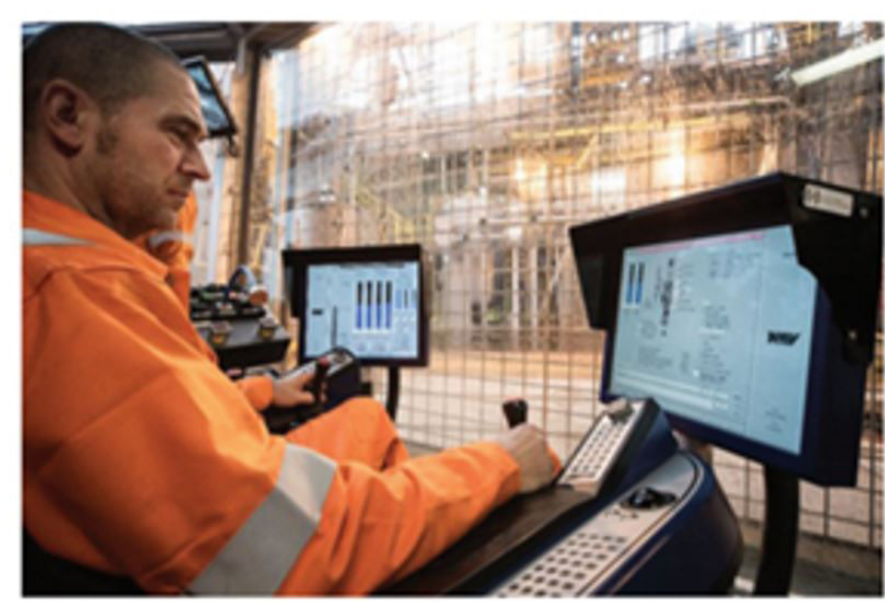

Figure 14. Automated Rig. Courtesy of Maersk Drilling (Roberts et al., 2019) in contrast to Non Automated Rig (McLeod, 2015).

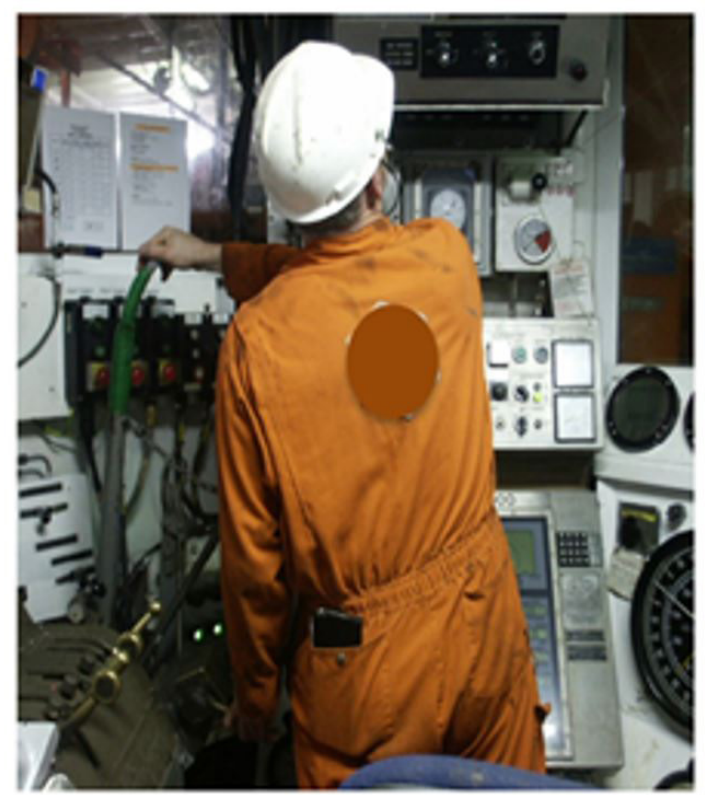

2018). Such automation clears the opportunity to operate rigs individually, with the driller operating all necessary equipment alone (Botnan, 2018).

The high level of automation enables the questioning of the effectiveness of operating a rig with a driller and an assistant driller. That said, a small research with offshore well operations employees is made to assess the real need or effective utilization of the driller + assistant driller configuration.

The form consisted on four questions in order to comprehend the frequency of a "two drillers" operation. The questions were:

- "Describe your function on board of a rig."

- "On the last year, you were present in rigs performing which type of operations the most (Drilling, Completion, Workover)?"

- "In a scale from 0 (never) to 10 (100\% of the time), how many times was the driller operating on his chair alone, without the assistant chair?"

• "Have you recently worked on a single driller rig?".

The respondents were 7 wellsite supervisors, 4 drillers and 1 toolpushter. The activities performed by them were described as: 5 Completion, 2 Drilling, 5 Workover. Results show that 11 out of 12 respondents consider the driller spends more than $70 \%$ of the time working on Single Driller mode, and 4 out of 12 evaluate the driller spends all the time working this way, independently of the presence of the auxiliary chair. It is important to clarify that the respondents state they worked more on Completion and Workover, that is, with less pipe handling. Another aspect is the fact that among 6 of those who indicate they already worked on a rig with a single chair, 5 are wellsite supervisors. It occurs because the Wellsite Supervisor often works in several rigs, as the driller and toolpusher are residents of a defined rig. If taken into account only the wellsite supervisors, 5 out of 7 responded they already worked on a single chair rig, which states that single driller operations are already a reality on offshore well operations. Also, the single driller operations can inspire methods and policies to implement single pilot operation safely, and with a vast knowledge background.

\section{Conclusions and Research Opportunities}

The present work was able to verify the structural alignment between the pilot and driller workstation, by presenting the possibilities of using CRM and HFACS and both industries, asserting the structural similarities between aviation and oil and gas regarding human factors. Also, a lateral thinking approach was used to present possibilities of exchange given the structural alignment, particularly on single pilot operations.

Upon completing this work, some research opportunities are highlighted, such as:

1. Single Driller Operations analysis in order to derive all the policies and handshakes from the drilling automation to an eventual single pilot automation.

2. Usage of the infrastructure from offshore drilling real time monitoring centers in order to test and apply concepts for real time monitoring and operations on aviation. 
3. Deriving the chain of command and hierarchy of a real time well operations monitoring to an eventual real time monitoring center on aviation, given single pilot specificities.

\section{References}

Blanchette, I., \& Dunbar, K. (2000). How analogies are generated: the roles of structural and superficial similarity. Memory \& Cognition, 28(1), 108-124.

Botnan, E. (2018). Drilling Control Rooms of the future. In Paper presented at the SPE/IADC Middle East Drilling Technology Conference and Exhibition. Abu Dhabi: Society of Petroleum Engineers.

De Bono, E. (2015). Lateral thinking. New York: Harper Perennial.

Faulhaber, A. K. (2019). From crewed to single-pilot operations: Pilot performance and workload management. In 67th International Symposium on Aviation Psychology. Dayton.

Gassmann, O., \& Zeschky, M. (2008). Opening up the solution space: the role of analogical thinking for breakthrough product innovation. Creativity and Innovation Management, 17(2), 97-106.

Gearhart, M. (2018). Human Factors and the Road to Single Pilot Operations. Bridgewater, MA: Bridgewater State University.

Gentner, D., \& Maravilla, F. (2017). Analogical reasoning. In L. J. Ball \& V. A. Thompson (Eds.), International Handbook of Thinking and Reasoning (pp. 186-203). New York: Psychology Press.

Gordon, R. P. (1998). The contribution of human factors to accidents in the offshore oil industry. Reliability Engineering \& System Safety, 61(1-2), 95-108.

Human Factors Analysis and Classification System - HFACS. (2014). The HFACS Framework. Washington, DC: Office of Aviation Medicine. Retrieved in 2019, November 10, from http://www.hfacs.com/hfacs-framework.html.

Hollaway, D., \& Johnson, J. (2014). Human Factors Analysis and Classification System (HFACS): Investigatory Tool for Human Factors in Offshore Operational Safety. In Offshore Technology Conference (pp. 1-119). Offshore Technology Conference.

Hope, T., Chan, J., Kittur, A., \& Shahaf, D. (2017). Accelerating innovation through analogy mining. In Proceedings of the 23rd ACM SIGKDD International Conference on Knowledge Discovery and Data Mining. Association for Computing Machinery.

Hutchins, E. (1995). How a cockpit remembers its speeds. Cognitive Science, 19(3), 265-288.
International Association of Drilling Contractors - IADC. (2019). Retrieved 10 November 2019, from https://www. iadc.org/safety-alerts/

International Civil Aviation Organization - ICAO. (2017). The Airbus Cockpit Philosophy. Retrieved 2019, November 15, from https://www.icao.int/ESAF/Documents/ meetings/2017/AFI\%20FOSAS\%202017/Day\%201\%20 Docs/Day_1_2_Airbuspihlo.pdf.

International Association of Oil \& Gas Producers - IOGP. (2014a). Human Factors, 2019.; Retrieved 2019, November 11.

International Association of Oil \& Gas Producers - IOGP. (2014b). IOGP Report 502: Guidelines for implementing Well Operations Crew Resource Management training. London: IOGP.

Iskandar, F. F., Abiddin, M. S. Z., Nazzeri, N., Aziz, A. A., \& Atemin, A. (2018). Integrated Real-Time Operation Centre: A Complete Solution towards Effective \& Efficient Drilling Operation. In Offshore Technology Conference Asia. Offshore Technology Conference.

Johnsen, S. (2014). Why are cognitive human factors missing from the blunt end in the oil and gas industry. In Proceedings of the XI Symposium on Human Factors in Organizational Design and Management-ODAM 2014 (pp. 699-704). IEA Press.

Kanki, B. G., Anca, J., \& Chidester, T. R. (2019). Crew resource management. Academic Press.

Lim, Y., Bassien-Capsa, V., Ramasamy, S., Liu, J., \& Sabatini, R. (2017). Commercial airline single-pilot operations: system design and pathways to certification. IEEE Aerospace and Electronic Systems Magazine, 32(7), 4-21.

McLeod, R. W. (2015). Designing for human reliability: human factors engineering in the oil, gas, and process industries. Waltham, MA: Gulf Professional Publishing, Elsevier.

Meister, D. (2003). Conceptual foundations of human factors measurement. CRC Press.

NOV (2018). Drilling Control Systems and Rig Automation. Retrieved 08 November 2019, 2019, from https://www.nov. com/-/media/nov/files/products/rig/rig-equipment/drillingcontrol-systems-and-rig-automation/amphion-integrateddrilling-control-system-brochure.pdf

Reid, D. (1998). The development of automated drilling rigs. In IADC/SPE drilling conference. Society of Petroleum Engineers.

Roberts, R. C., Flin, R., Cleland, J., \& Urquhart, J. (2019). Drillers' cognitive skills monitoring task. Ergonomics in Design, 27(2), 13-20.

Theophilus, S. C., Esenowo, V. N., Arewa, A. O., Ifelebuegu, A. O., Nnadi, E. O., \& Mbanaso, F. U. (2017). Human 
factors analysis and classification system for the oil and gas industry (HFACS-OGI). Reliability Engineering \& System Safety, 167, 168-176.

USA. (2012). 14 CFR 121.385 - Composition of flight crew.
Wickens, C. D., Gordon, S. E., \& Liu, Y. (2014). An introduction to human factors engineering (2nd ed.). Upper Saddle River, NJ: P. E. Limited Ed.

Wiegmann, D. A., \& Shappell, S. A. (2017). A human error approach to aviation accident analysis: The human factors analysis and classification system. London: Routledge. 